\title{
Thyroid Rosai-Dorfman disease with infiltration of IgG4-bearing plasma cells associated with multiple small pulmonary cysts
}

\author{
Pietro Gianella ${ }^{* *} \mathbb{D}$, Nicolas Dulguerov², Grégoire Arnoux ${ }^{3}$, Marc Pusztaszeri ${ }^{3}$ and Jörg D. Seebach ${ }^{4}$
}

\begin{abstract}
Background: Rosai-Dorfman disease (RDD) is a rare histiocytosis which involves principally lymph nodes. Thyroid involvement in RDD is a very rare situation, and lung involvement is even rarer.

Case presentation: We report the case of a 46-year-old woman presenting a painless mass in the right side of the neck and subacute dyspnoea. Computerised tomography (CT) scans of the neck and thorax showed a large thyroid mass causing tracheal stenosis and multiple cystic lesions in both lungs. Subtotal thyroidectomy with a tracheal segment resection and histological analysis confirmed the diagnosis of nodal and extranodal (thyroid, tracheal and probably lung) Rosai-Dorfman disease (RDD) with the presence of increased numbers of IgG4-bearing plasma cells. Clinical, functional and radiological follow up 4 years after surgery without medical treatment did not show any disease progression.

Conclusions: This case report indicates a benign course of nodal RDD with thyroid and tracheal infiltration following surgical resection, association of typical histological signs of RDD (emperipolesis) with IgG4-related disease features, and that lung cysts might be a manifestation of RDD.
\end{abstract}

Keywords: Rosai-Dorfman disease, Non-Langerhans cell histiocytosis, Lungs cystic lesions

\section{Background}

According to the recent classification published by Emile and colleagues Rosai-Dorfman disease (RDD), also known as sinus histiocytosis with massive lymphadenopathy, is a rare non-Langerhans cell histiocytosis which involves principally lymph nodes [1]. Diagnosis depends on biopsies with immunostaining demonstrating infiltration with histiocytes positive for CD68+/S100+, negative for CD1a and CD207 excluding pulmonary Langerhans cell histiocytosis (PLCH); and the presence of intact lymphocytes within the histiocyte cytoplasm (known as emperipolesis). Although emperipolesis is not pathognomonic and can be seen in other conditions, most notably Erdheim-Chester disease and hemophagocytic lymphohistiocytosis, it is highly suggestive for RDD.

\footnotetext{
*Correspondence: pietro.gianella@eoc.ch

'Division of Pulmonary Diseases, Geneva University Hospitals, 4 Rue

Gabrielle-Perret-Gentil, 1211, 14 Geneva, Switzerland

Full list of author information is available at the end of the article
}

Extranodal involvement occurs in up to $43 \%$ of cases with skin, central nervous system, and salivary glands as the most frequently reported sites. Only a few hundred cases of RDD are altogether reported in the literature [2-4]. Thyroid and respiratory tract involvement has been described in less than $3 \%[3,5,6]$, with only one case of concomitant thyroid and lung involvement [7]. Besides mediastinal lymphadenopathy, tracheal and bronchial involvement, nodular masses, bronchiectasis, pleural effusion, and interstitial infiltrates have been reported. In the majority of cases, RDD has a benign course and treatment is not necessary. Therapy is required for patients with extranodal RDD having vital organ involvement or those with nodal disease causing life-threatening complications. Complete remission can often be achieved after surgical excision. Systemic corticosteroids are the most effective medical treatment in case of systemic symptoms or symptomatic lymph nodes enlargement $[3,4]$.

(c) The Author(s). 2019 Open Access This article is distributed under the terms of the Creative Commons Attribution 4.0 International License (http://creativecommons.org/licenses/by/4.0/), which permits unrestricted use, distribution, and reproduction in any medium, provided you give appropriate credit to the original author(s) and the source, provide a link to the Creative Commons license, and indicate if changes were made. The Creative Commons Public Domain Dedication waiver (http://creativecommons.org/publicdomain/zero/1.0/) applies to the data made available in this article, unless otherwise stated. 


\section{Case presentation}

A 46-year-old never smoker Malagasy woman was referred by her family doctor to the emergency department due to dyspnoea with inspiratory stridor and inspiratory-expiratory wheezing with insidious onset over a 3-month period. The patient was treated for supposed asthma since 2 weeks without improvement. She had no fever, weight loss or night sweats. Physical examination revealed a heart rate of $96 / \mathrm{min}$, a respiratory rate of $19 / \mathrm{min}$, and an oxygen saturation of $89 \%$ on room air with normal chest auscultation. A non-tender mass was detected on the right side of her neck.

CT scans of the neck and thorax showed a large thyroid mass causing tracheal stenosis (Fig. 1a), and multiple cystic lesions with thin walls in both lungs (Fig. 1b). Cysts had a diffuse localisation, including the costophrenic recesses. Neither pulmonary nodules nor ground glass opacities were observed. Abdominal CT scan did not show any sign of renal angiomyolipoma.

Blood arterial gases showed mild hypoxemia $(\mathrm{PaO} 282$ $\mathrm{mmHg}$ ). Laboratory investigations, including renal function, liver function tests, C-reactive protein, thyroid function tests, complete blood cell counts, and serum IgG4 levels were all within normal limits. HIV and immunological tests (anti-Ro/SSA and anti-La/SSB antibodies, rheumatoid factor and thyroid-stimulating hormone (TSH) receptor antibody) were negative. Plasma levels of vascular endothelial growth factor-D (VEGF-D) were low $(347 \mathrm{pg} / \mathrm{mL}$; normal range $0-450$ $p g / m L)$. Electrocardiogram (ECG) tracing and complete pulmonary function testing were normal (forced expiratory volume in $1 \mathrm{~s}$ - FEV1 94\%, total lung capacity TLC of $95 \%$ of predicted and normal carbon monoxide diffusing capacity - DLCO).

Surgical removal of the thyroid mass with subtotal thyroidectomy, tracheal segment $(3.5 \mathrm{~cm})$ resection and multiple adenectomies were performed (Fig. 2). Microscopic study revealed extensive infiltration of all lymph nodes and the thyroid with partial replacement of follicular parenchyma by a fibro-inflammatory process of mixed cellularity, rich in histiocytes (Fig. 3a). The latter exhibited epithelioid to xanthomatous morphology and formed ill-defined clusters or confluent sheets without granulomatous pattern. An important fraction of the histiocytic population showed emperipolesis of neutrophil granulocytes and lymphocytes (Fig. 3b). Immunohistochemistry revealed co-expression of the macrophage-related epitope CD68 along with S100 protein, in the absence of CD1a, thereby identifying the histiocytic elements as of non-Langerhans lineage (Fig.4a, 4b and 4c). Remarkably, storiforme fibrosis with signs of vasculitis was also observed and immuno-phenotyping of the infiltrate revealed a substantial participation of IgG4-bearing plasma cells. While their absolute density reached up to 50 per high power field, the IgG4:IgG ratio did not exceed 20\% (Fig.4d). Histological examination of the tissue biopsies for the identification of infectious organisms using several stainings for pathogens were negative. Based on these findings, a histological diagnosis of RDD was made.

Following surgery dyspnoea disappeared indicating that it was related to tracheal compression. The patient was asymptomatic in the absence of any specific treatment; clinical, functional lung testing and radiological follow up 4 years after surgery did not reveal any disease activity or progression underlining the excellent prognosis of the disease after resection.

\section{Discussion and conclusions}

Our patient presents the very uncommon association of thyroid, tracheal and nodal RDD with multiple small lung cysts. Only few cases of lung cysts associated with RDD are described in the literature. In fact, a recent Mayo case series of 9 patients with intrathoracic manifestations of RDD mainly found mediastinal lymph node involvement. However, there were two patients (\#4 and \#9) with lung cysts and bronchiectasis [6]. Moreover,
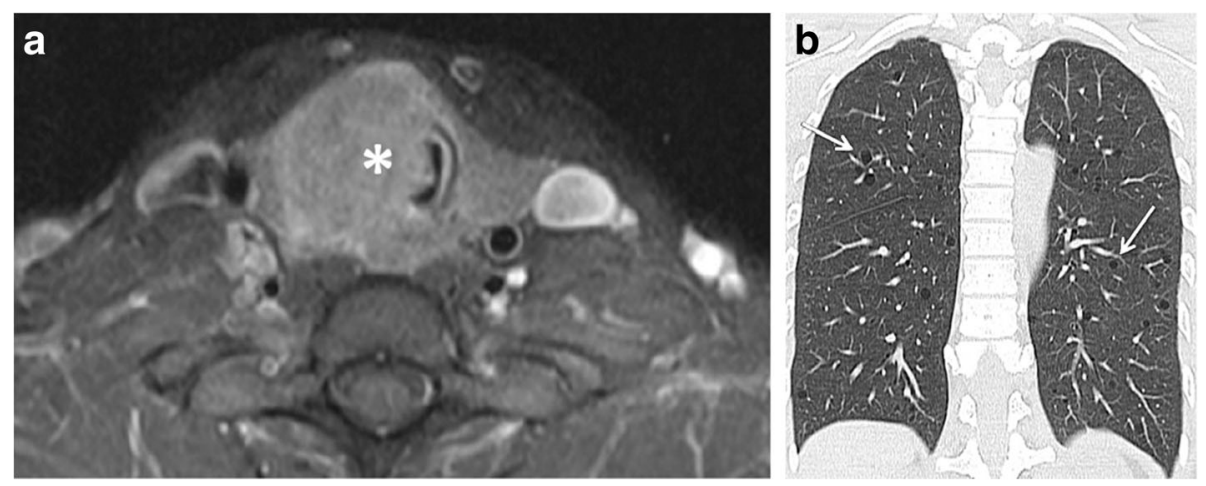

Fig. 1 Neck CT scan (axial reconstruction) showing a large right sided thyroid mass (asterisk) which caused marked tracheal deviation and stenosis (a). Thorax CT scan (coronal reconstruction) showing multiple cystic lesions with thin wall in both lungs (arrows) (b) 


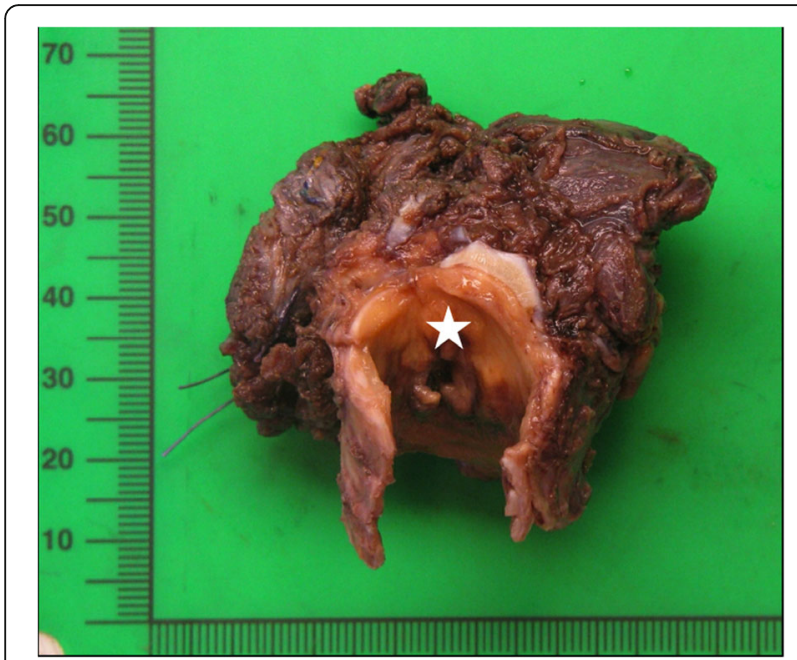

Fig. 2 Surgical specimen showing a poorly delimited infiltrative whitish thyroid mass with extension to the adjacent tracheal structure. Star indicates the luminal surface of the trachea

cystic lung disease has developed over time in a patient presenting with consolidative nodules, pleural thickening, septal lines, and mediastinal lymphadenopathy. The diagnosis of pulmonary RDD was established by open-lung biopsy [8]. Another patient with cutaneous RDD showed bilateral pulmonary cysts and numerous ground glass nodules with characteristic upper lobe predominance. There was no intrathoracic lymphadenopathy or pleural effusion mimicking PLCH. However, the biopsy of the concomitant skin lesion confirmed the histological diagnosis of RDD [9]. Thus, cyst-formation is possible in pulmonary RDD, it is however very rare and likely to be accompanied by other pulmonary radiographic findings, suggestive of interstitial lung disease. The main differential diagnosis of pulmonary cysts included PLCH, lymphocytic interstitial pneumonia (LIP), or lymphangioleiomyomatosis (LAM) [10, 11]. In fact, histiocytosis (e.g. PLCH and Erdheim-Chester disease) frequently cause cystic lung disease with a mid to upper zone predominance [12]. Nevertheless, the absence of tobacco consumption, the diffuse cysts localisation and the absence of peribronchiolar nodular opacities all argued against PLCH. Moreover, the patient did not present any of the typical features of Erdheim-Chester disease. The clinical presentation as well as the absence of pulmonary nodules and ground glass opacity was atypical for LIP. Furthermore, human immunodeficiency virus (HIV) and immunological tests (anti-Ro/SSA and anti-La/SSB antibodies, rheumatoid factor and TRAb) were negative. Genetic testing for Birt-Hogg-Dube syndrome (BHDS) was not performed since there was no family history, no extrapulmonary manifestations, such as skin lesions or renal cancer, and the distribution of the cysts was not suggestive. Lung cysts in BHDS are multiple, thin walled, typically seen in the peripheral zones at lung bases and along the mediastinum with a disproportionate number of paramediastinal elliptical (floppy) cysts, and can abut or encase the proximal portion of the lower pulmonary veins [11]. In contrast, the multiple small and thin-walled lung cysts in the presented case were higher in number and diffusely distributed throughout the lung parenchyma, more ressembling the distribution in LAM. The radiologic appearance of the cysts, age and sex of the patient were indeed compatible with LAM. The VEGF-D plasma level was low $(347 \mathrm{pg} / \mathrm{mL})$ neither confirming nor excluding LAM since VEGF has a good positive predictive value if the value is greater than $600 \mathrm{pg} / \mathrm{mL}$ but a poor negative predictive value below this threshold [13]. In addition, abdominal CT scanning did not show any sign of renal angiomyolipoma which is associated to LAM in $50 \%$ of the cases. Taken together, without lung biopsy the observed cystic lung lesions cannot with certainty be attributed to RDD, since a concomitant diagnosis of LAM

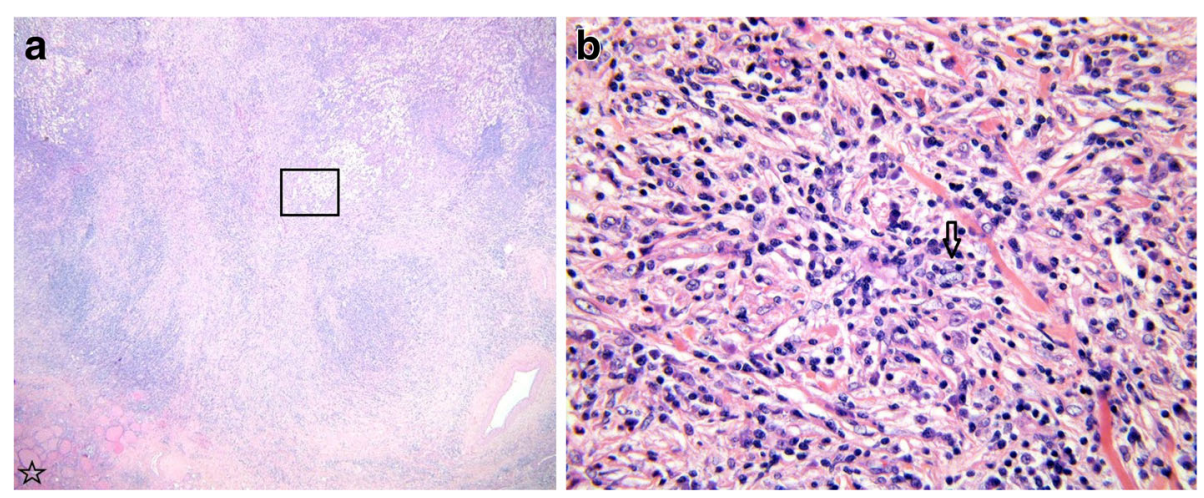

Fig. 3 a Overview of one representative fragment showing a dense fibro-inflammatory process involving the thyroid and the tracheal wall (boxed area). The star indicates residual thyroid tissue. b Detail view of the boxed area in (A) showing predominant histiocytic infiltrates along with numerous emperipolesis figures, i.e. histiocytes engulfing neutrophil granulocytes and lymphocytes (arrow head). This combination is a prominent feature of Rosai-Dorfman disease. H\&E staining; original magnification: A $\times 20$; $\times 400$ 


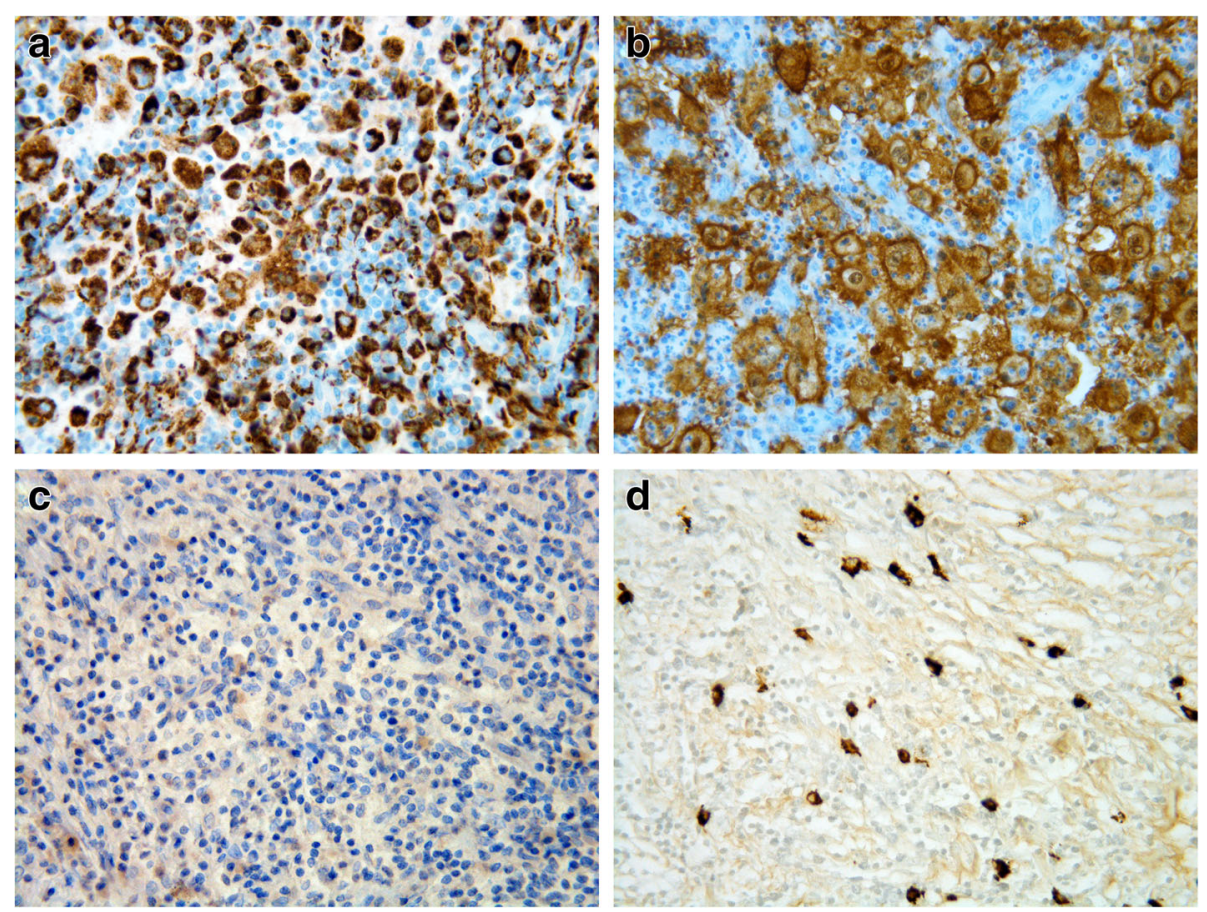

Fig. 4 Detailed view of the immunostaining results showing histiocytes strongly positive for CD68 (a) and S100 (b), negative staining for CD1a (c), and increased numbers of IgG4-bearing plasma cells (d). Original magnification A-D $\times 400$

or BHDS was not completely ruled out. Although two rare diseases may coexist in the same patient, it is preferable to retain a single etiology and unifying diagnosis. Therefore, in analogy to other histiocytosis known to cause lung cysts the pulmonary lesions in our case are probably related to RDD.

In general, associated autoimmune diseases can be found in 13\% of RDD. As demonstrated in the our case a subset of patients with RDD present increased levels of IgG4-bearing plasma cells upon immunohistological examination rendering the differential diagnosis with IgG4-related disease somewhat difficult [1, 14]. The overlap between RDD and IgG4-related disease with the two conditions sharing similar features, including emperipolesis, may represent a spectrum $[15,16]$, whereas other authors suggest differentiation between the two based on the degree of IgG4-positive infiltrates and IgG4:IgG ratio [17]. Menon et al. reported the presence of IgG4-bearing plasma cells in 28/70 RDD cases (40\%) with $17.4 \%$ fulfilling the consensus guideline criteria for a histological diagnosis of IgG4-related disease [18]. Of note, the two cases of intrathoracic RDD with elevated IgG4-bearing plasma cells presented with pulmonary masses and not with cysts. The presence of abundant emperipolesis was highly suggestive for RDD and the levels of IgG4-bearing plasma cells insufficient to make a diagnosis of IgG4-related disease. However, the significance of IgG4-bearing plasma cells in RDD remains to be further elucidated, and their presence might indicate a better treatment response to corticosteroids and/or rituximab in case of disease progression.

In conclusion, this case report indicates a benign course of nodal RDD with thyroid and tracheal infiltration following surgical resection, describes an association of typical histological signs of RDD (emperipolesis) with IgG4-related disease features, and that lung cysts might be a manifestation of RDD.

\section{Abbreviations}

BHDS: Birt-Hogg-Dube syndrome; LAM: Iymphangioleiomyomatosis; LIP: Iymphocytic interstitial pneumonia; PLCH: Pulmonary Langerhans cell histiocytosis; RDD: Rosai-Dorfman disease; VEGF-D: Vascular endothelial growth factor-D

\section{Acknowledgements}

Not applicable.

\section{Funding}

No funding was obtained for this study.

Availability of data and materials Not applicable.

\section{Authors' contributions}

P.G. coordinated the study; P.G. and J.D.S. were in charge of patient \& acquired the data. P.G., M.P., \& J.D.S wrote the first draft of the manuscript. All authors corrected subsequent versions and approved the final version of the manuscript.

Ethics approval and consent to participate Not applicable. 


\section{Consent for publication}

a written consent from patient was obtained to publish this case report.

\section{Competing interests}

P. G. has nothing to disclose, N. D. has nothing to disclose, G.A. has nothing to disclose, M.P. has nothing to disclose, J.D.S. has nothing to disclose.

\section{Publisher's Note}

Springer Nature remains neutral with regard to jurisdictional claims in published maps and institutional affiliations.

\section{Author details}

'Division of Pulmonary Diseases, Geneva University Hospitals, 4 Rue Gabrielle-Perret-Gentil, 1211, 14 Geneva, Switzerland. ${ }^{2}$ Division of Head and Neck Surgery, Geneva University Hospitals, Geneva, Switzerland. ${ }^{3}$ Department of Clinical Pathology, Geneva University Hospitals, Geneva, Switzerland. ${ }^{4}$ Division of Immunology and Allergy, Geneva University Hospitals, Geneva, Switzerland.

Received: 5 October 2018 Accepted: 15 April 2019

Published online: 03 May 2019

\section{References}

1. Emile JF, Abla O, Fraitag S, Horne A, Haroche J, et al. Histiocyte society. Revised classification of histiocytoses and neoplasms of the macrophagedendritic cell lineages. Blood. 2016;127(22):2672-81.

2. Rosai J, Dorfman RF. Sinus histiocytosis with massive lymphadenopathy. A newly recognized benign clinicopathological entity. Arch Pathol. 1969;87(1): 63-70.

3. Foucar E, Rosai J, Dorfman RF. Sinus histiocytosis with massive lymphadenopathy (Rosai-Dorfman disease): reviewing of the entity. Semin Diagn Pathol. 1990;7(1):19-73.

4. Foucar E, Rosai J, Dorfman RF. Sinus histiocytosis with massive lymphadenopathy: ear, nose, and throat manifestations. Arch Otolaryngol. 1978:104:687-93.

5. Lee FY, Jan YJ, Chou G, Wang J, Wang CC. Thyroid involvement in RosaiDorfman disease. Thyroid. 2007;17(5):471-6.

6. Cartin-Ceba R, Golbin JM, Yi ES, Prakash UBS, Vassallo R. Intrathoracic manifestations of Rosai-Dorfman disease. Respir Med. 2010;104(9):1344-9.

7. Ben Ghorbel I, Naffati H, Khanfir M, Kchir MN, Mrad K, et al. Disseminated form of Rosai-Dorfman disease. A case report. Rev Med Interne. 2005;26(5): 415-9.

8. Goupil de Bouillé J, de Muret A, Diot E, Dumont P, Plantier L, et al. Pulmonary manifestations revealing Rosai-Dorfman disease. Sarcoidosis Vasc Diffuse Lung Dis. 2015;32(3):275-7.

9. AL Umairi R, Blunt D, Hana W, Matthew Cheung M, Oikonomou A. RosaiDorfman disease: rare pulmonary involvement mimicking pulmonary langerhans cell histiocytosis and review of the literature. Case Rep Radiol. 2018.

10. Raoof S, Bondalapati P, Vydyula R, Ryu JH, Gupta N, et al. Cystic lung diseases: algorithmic approach. Chest. 2016;150(4):945-65.

11. Escalon JG, Richards JC, Koelsch T, Downey GP, Lynch DA. Isolated cystic lung disease: an algorithmic approach to distinguishing Birt-Hogg-Dubé syndrome, Lymphangioleiomyomatosis, and lymphocytic interstitial pneumonia. AJR Am J Roentgenol. 2019;19:1-5.

12. Brun AL, Touitou-Gottenberg D, Haroche J, Toledano D, Cluzel P, et al. Erdheim-Chester disease: CT findings of thoracic involvement. Eur Radiol. 2010;20(11):2579-87.

13. Young LR, Inoue $Y, M c C o r m a c k ~ F X$. Diagnostic potential of serum VEGF-D for lymphangioleiomyomatosis. N Engl J Med. 2008;358(2):199-200.

14. Apperley ST, Hyjek EM, Musani R, Thenganatt J. Intrathoracic rosai dorfman disease with focal aggregates of IgG4-bearing plasma cells. Case report and literature. Add Ann Am Thorac Soc. 2016;13(5):666-70.

15. Shrestha B, Sekiguchi H, Colby TV, Graziano P, Aubry MC, et al. Distinctive pulmonary histopathology with increased lgG4-positive plasma cells in patients with autoimmune pancreatitis: report of 6 and 12 cases with similar histopathology. Am J Surg Pathol. 2009:33(10):1450-62.

16. Zhang $X$, Hyjek $E$, Vardiman J. A subset of Rosai-Dorfman disease exhibits features of IgG4-related disease. Am J Clin Pathol. 2013;139(5):622-32.
17. Liu L, Perry AM, Cao W, Smith LM, Hsi ED, et al. Relationship between RosaiDorfman disease and IgG4-related disease: study of 32 cases. Am J Clin Pathol. 2013;140(3):395-402.

18. Menon MP, Evbuomwan MO, Rosai J, Jaffe ES, Pittaluga S. A subset of RosaiDorfman disease cases exhibit increased lgG4 positive plasma cells: another red herring or a true association with lgG4 related disease? Histopathology. 2014;64(3):455-9.

\section{Ready to submit your research? Choose BMC and benefit from:}

- fast, convenient online submission

- thorough peer review by experienced researchers in your field

- rapid publication on acceptance

- support for research data, including large and complex data types

- gold Open Access which fosters wider collaboration and increased citations

- maximum visibility for your research: over $100 \mathrm{M}$ website views per year

At $\mathrm{BMC}$, research is always in progress.

Learn more biomedcentral.com/submissions 